\title{
Communicating Risks to Patients and the Public
}

\author{
Norbert Leitgeb \\ Institute of Health Care Engineering, Graz University of Technology, Austria
}

Copyright (C) 2016 by authors, all rights reserved. Authors agree that this article remains permanently open access under the terms of the Creative Commons Attribution License 4.0 International License

\begin{abstract}
It is well known from everyday life that communication is difficult. However, it is an even greater challenge to communicate sensitive or controversial issues such as risks in particular in emotional situations. Consequently, risk communication is much more than just talking about an issue. It requires specific knowledge, tailoring and targeting information to the patient's needs and abilities, and observing communication rules. The most frequent mistake is underestimating the need for specific skills and ignoring the pitfalls and dos and don'ts of risk communication. The basic information is given and demonstrated by various examples.
\end{abstract}

Keywords Risk Communication, Targeting, Literacy, Framing, Pitfalls

\section{Introduction}

In medicine, risk communication is becoming increasingly important with regard to the request of evidence-based patient counseling by physicians to enable patients to informed decisions on existing options based on associated risks and benefits. However, risk communication is not just talking about an issue. It is much more. Theoretically, risk communication means identification, assessment and communicating risks to stakeholders, usually from experts to lay people. Even more general, risk communication could be understood as communicating controversial or sensitive issues, frequently hampered by emotions. However, nobody can be expert in every field. Therefore, even an expert (in a particular field) may change its role and become a layperson with regard to other issues.

It is known from everyday life that already conventional communication is difficult, and the probability of misunderstanding high. This is even worse in risk communication. Therefore, risk communication requires evidence-based factual knowledge about the risk factor, specific communication skills, awareness of the recipient's background and needs and, consequently, targeted messages with adequate wording, tailored information, and avoiding pitfalls by observing dos and don'ts.

Risk is understood as product of harm and its probability of occurrence, and hence requires knowledge on two main estimates. However, since a risk factor usually affects several health endpoints, it is a challenge to weigh the various particular risks such as lethality or pain and associated benefits such as survival and life quality to come to an overall assessment. Since risks would hardly be acceptable if there were no benefits, risk need to be weighted against them. Consequently, the issues of risk communication are risks, benefits and existing alternatives such as by informing on the benefit of earlier cancer detection by X-ray screening at the expense of potential cancer induction and other unintended side-effects, and comparing them to the situation in alternatives such as magnetic resonance screening or no screening at all.

\section{Patients}

Recipients in risk communication are no blank sheets. They have their educational background with probably incomplete or erroneous knowledge, inadequate mental models of the nature of risk factors, associated risks and dose-responses, as well as their individual interests, convictions, believes and, very important, their emotions. Consequently, individual risk perception varies considerably from person to person. It is almost independent from quantitative risk assessment. This is easily demonstrated by perceived risks such as from smoking, tanning or car driving which are usually underestimated compared to risks from using aircrafts, mobile telephones or living close to power lines which are frequently overestimated.

There are factors which enhance and others which downplay perceived risk. The interaction of these factors are summarized in the risk balance as shown in Figure 1.

The perceived threat of a risk is enhanced by the attributed horribleness of a factor such as nuclear power plants, unfairness such as being exposed while others are not, ignorance with associated enhanced caution against the unknown, or even stigmatization, in the latter case with resistance against any further argument or reasoning such as in the field of vaccination. On the other hand, the perceived risk may be downplayed by personal or social benefits, the feeling of controllability, the familiarity with a factor such as cars and personal attitude towards risk tolerance (which is usually lower in women compared to men). 


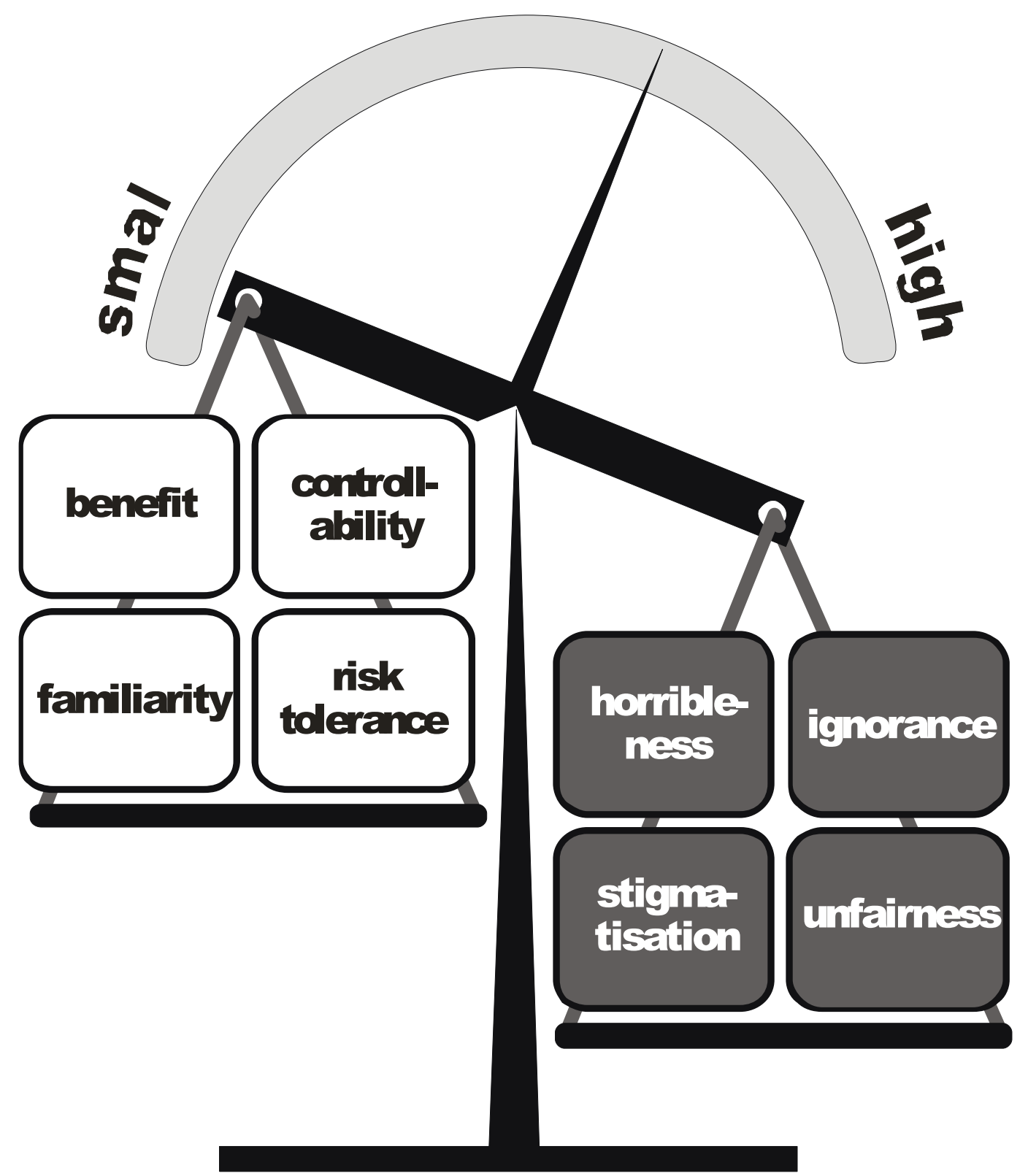

Figure 1. Risk perception balance with risk enhancing and risk downplaying parameters

\section{Objectives}

Medical risk communication has two main objectives: to inform about an issue such as risks, benefits and options, and to enable patients to decide on an adequate action. However, there are many obstacles on the long way from information to action (Figure 2) such as patient's limited cognitive abilities as caused by deficits in literacy and numeracy and emotional filtering, misunderstanding due to erroneous mental models, fragmentary and/or erroneous background knowledge, and potential mistrust such as provoked by emotions and doctor's body language contradicting the message.

However, providing information does not already assure that it is understood, and if so, it is not sure whether it is understood correctly, and if so, it is not sure whether it is believed, and if so, it is not sure whether patient's fear, moral or faith might overrule a given advice such as in case of faith-based refusal of blood transfusions. But even when a decision is made there are still barriers to overcome such as financing, timely access to medical service or just the patient's phlegm to finally act accordingly (Figure 2).

These obstacles require tailoring information to patient's needs, identifying and correcting potential erroneous thinking and convincing arguing. 


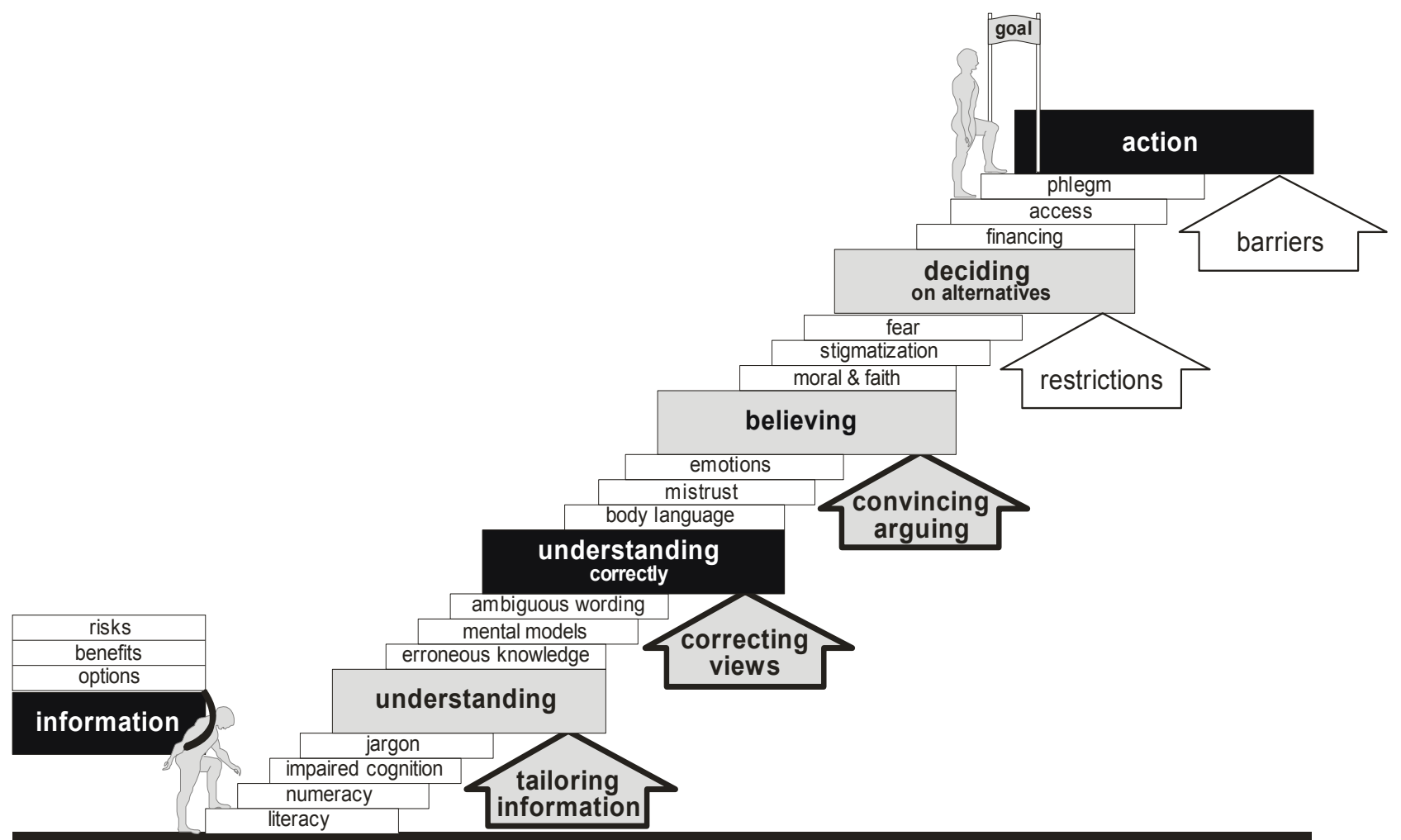

Figure 2. Obstacles of risk communication on the long way and from information to action

\section{Presentation}

Risk communication needs considering the patient's profile. It should be targeted to patients, to their needs, interests and abilities, clearly structured, straight-forward, easy worded, redundant and convincing [3,15,16] (Figure 3). However, proper and efficient risk communication is not for free. Apart from basic knowledge about risk communication and evidence-based factual expertise of risks and benefits of the particular factor it requires preparation time. It has become a well-known anecdote saying, it would possible to immediately give a lecture of unrestricted duration, however, needs some days to prepare a 10min speech. This is explained by the challenge to decide what and how to communicate, what to say but also what not to say.

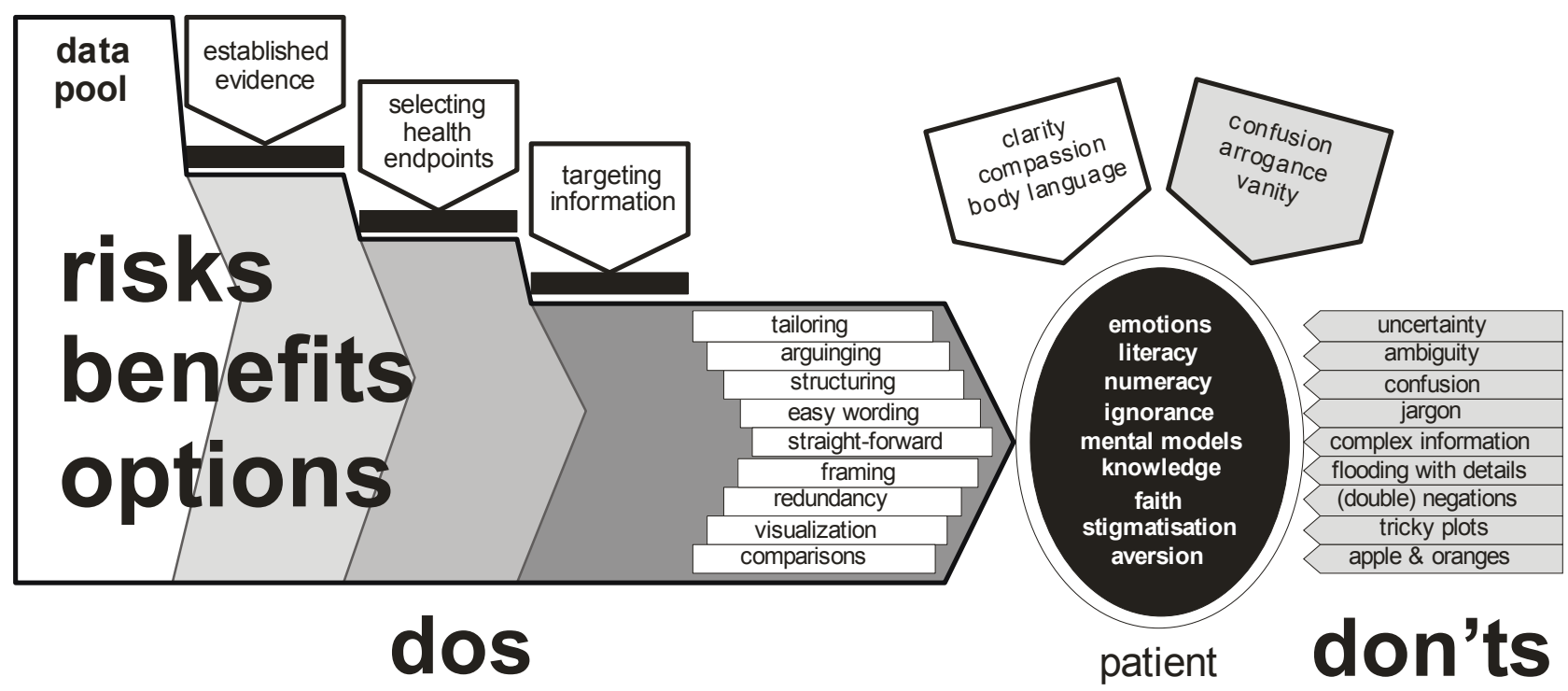

Figure 3. Dos and don'ts in risk communication 
Patient's abilities are limited such as with regard to literacy and numeracy. In spite of many years of education, even in industrialized countries every $7^{\text {th }}$ adult is a functional illiterate and every $5^{\text {th }}$ adult may be able to read but not to understand written information $[3,5,7,8]$. In addition, the consequence of the "use it or lose it" effect is seen in even lower literacy of elderly. USA studies report almost three quarters $(71 \%)$ of adults older than 60 years having difficulty in using printed materials such as prescription of medication $[3,17]$. It is frequently ignored that impaired literacy limits efficiency of written information. An impressing curious example is the inadequate warning label at a product "if you cannot read the warnings, don not use the device!"

However, there are also limitations in understanding, using and interpreting numerical information. In the USA more than two thirds $(68 \%)$ of the adult population have difficulties in understanding percentages, and almost a quarter of college-educated adults were unable to correctly decide which was a higher risk $1 \%, 5 \%$ or $10 \%$ [3]. Consequently, this limited numeracy needs to be taken into account in presenting quantitative information by avoiding stand-alone numbers without further verbal and/or graphical assistance.

This requires adequate structuring communication and explains why in medical device safety standards a lay person is defined as a 14 year old person [1]. Impaired literacy poses restrictions on wording and vocabulary and limited numeracy requires careful use of quantitative information and assistance by illustration such as by plots and/or comparisons.

Emotions play an important role in risk communication. The exceptional situation of patients, their stress and fear, emotions and pain further complicate risk communication. They considerably reduce patient's intellectual skills, perception capability and cognitive performance by up to three quarters with only $25 \%$ remaining compared to normal.

Targeted information should account for the patient's cultural and intellectual background and be tailored to patient's needs. It should not be a scientific lecture such as about history, physical background, hypotheses, challenges and hopes, but should contain only information which is relevant for the patient in her/his specific situation - not less but not more. It should be clear that these needs change with patient's situation and progress of disease.

Clear structuring requires preparation time. It assures to keep track and provide information step by step to enable logic and convincing arguing, and proper understanding.

Straight forward means bringing messages to the point by selecting the relevant facts without boring and unnecessary information and, very important, to avoid the need for mental conversion with regard to wording, numbers and visual illustrations in particular with regard to the limitations in literacy and numeracy.

To avoid mental conversion it should be abstained from using complicated numbers such as percentages, per milles, fractions etc.. The numbers 0.25 or $25 \%$ are much more difficult to understand than "one out of four" (Figure 4,
Figure 5) but "20 out of 60 " would also need some conversion and should be shortened to lowest whole numbers, in the given example such as "one out of three".

Things become even worse with regard to orders of magnitudes. This is demonstrated in the following two versions of a statement

1. "dental X-ray exposure is 1000 fold lower than
exposure from abdominal CT scanning"
2. "dental X-ray exposure is 1000fold lower than 2. "dental $X$-ray abdominal CT scanning like the size of a pebble compared to a church spire"

The first version is hardly understood. However, it could be improved by assistance of a vivid comparison such as in version 2.

In addition to numbers, simple graphs are useful for enhancing both understanding and credibility such as bar plots for numerical comparisons, pie charts for proportions or pictograms for the numbers of affected persons [3,14]. However, figures which need mathematical skills such as counting, dividing etc. should be avoided. Illustrating $25 \%$ by 100 manikins with 25 of them in different colour is much more difficult to interpret than the version with the lowest numbers such as one manikin out of 4 (Figure 4, 5). Even more difficult to understand are tricky diagrams such as coding numbers by the area of a circle (based on a square-law relationship) or volume of an object (based on a cubic-law relationship). Diagrams with complex curves are a considerable obstacles for the majority, however, diagrams with a logarithmic scale are an absolute no-go. They ignore the wide-spread linear thinking and should be restricted to a scientific community.

Therefore, the golden rule also of plots is to be as simple as possible and to present visual information in a way allowing first-glance understanding without the need of any mental conversion (Figure 4, 5).

\section{$0,25 \quad 25 \% \quad 1 / 4 \quad 3$ out of 12}

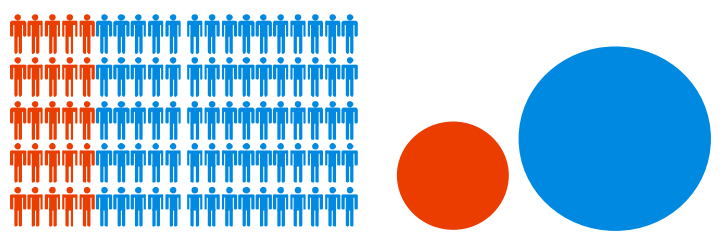

Figure 4. Numbers (above) and illustrating plots (below) needing numeracy and mental conversion to understand 1 out of 4

\section{1 out of 4}

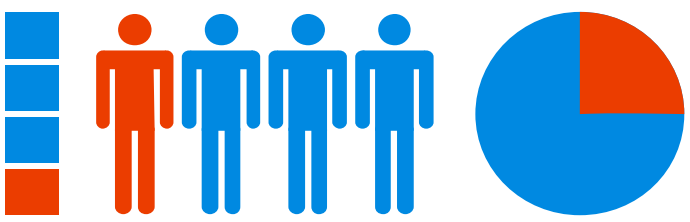

Figure 5. Numerical information (above) and illustrating plots (below) which don't need neither numeracy nor mental conversion

Easy wording is a challenge. Messages should be clear and straight forward as demonstrated by the following 
versions of the same message:

1. "The risk of complications is $0.3 \%$."

2. "Three out of thousand are at risk of complications."

While the first version needs numeracy skills and mental conversion the second is more easily understood. However, the magnitude 1000 still remains a challenge for understanding. Therefore, for further improvement it should be illustrated by a comparison with well-known quantities or objects such as in version 3 of the message:

3. "Three out of thousand are at risk of complications, which is about the same relation as the length of a baby compared to the height of a TV tower ."

As a guidance, it should be imagined to talk to a 14 year old child. This is more difficult than expected. It means overcoming own vanity and avoiding arrogance, abstaining from specialized terms such as Latin names and medical jargon but using every day language and pictorial comparisons.

However, even common words may be a source of misunderstanding and/or misinterpretation and, hence, of impaired communication even if they are readily understood [10]. This can be demonstrated in verbal classifying the level of evidence. An example is the use following (unordered) verbs to indicate the strength of evidence:

suggested / convincing / probable / established / possible.

Tests have shown that there is no order which is equally understood by everybody and, hence, generally agreed. (A frequently accepted order would be: established / convincing / probable / possible / suggested.) Understanding could be improved by using or adding numbers to verbs such as ranks from 1 to 5 to further clarify the order.

However, even numbering can lead to pitfalls since it remains still unclear whether a high number is the best or worst grade. One reason is that grading systems in schools differ among countries such as with the highest number allocated for the best grade in countries such as Norway, Switzerland, Finland, Hungary or Croatia and the quite contrary with 1 as best grade in others.

In addition, communication should be logic and self-explaining. This is not self-evident as demonstrated in
Table 1. An example is the grading of WHO's International Agency for Research on Cancer (IARC) which classifies carcinogenicity in a puzzling scheme in an illogic order, namely

\section{class $1 /$ class $2 A$ / class $2 B$ / class 3 / class 4}

with neither equal stepping (by subdividing one class) nor with intuitive ordering with the jolly joker 3 (unclassifiable) right in the midst of the scale although unclassifiable means there is no specific class at all, and the highest grade for zero carcinogenicity with the illogic equality $4=0$. To improve understanding, IARC amended numbers by verbal characterization as follows:

1: carcinogenic / 2A: probably carcinogenic / 2B: possibly carcinogenic / 3: not classifiable / 4: probably not carcinogenic.

However, even now there is some difficulty remaining concerning common understanding of the difference of the terms "probably" and "possibly".

A clearer communication would be achievable by combining verbs and numbers, equally stepping and logic order with zero dedicated to zero evidence [9]. An example is the level of evidence (E) scheme of the German Commission on Radiation Protection (SSK), namely:

E3: convincing evidence / E2: incomplete evidence / E1: weak evidence / E0: lack of evidence/EN: evidence of lacking causality.

Since "unclassifiable" does not allow any conclusion, it must not be placed at any place in an evidence scale. In particular "lack of data" must not be confused with "lack of evidence" for causality. Consequently, SSK used an additional grading to characterize data which are inadequate for concluding on evidence.

Redundancy in risk communication is necessary to account for the fact that emotions considerably reduce cognitive performance. However, redundancy should not be boring by just repeating the same with the same words again and again but provide similar information in different ways and/or channels such as by using numbers, verbs and plots.

Table 1. Examples of scaling evidence; IARC... International Agency for Research on Cancer, SSK...German Commission on Radiological Protection

\begin{tabular}{|c|c|}
\hline $\begin{array}{c}\text { carcinogen } \\
\text { class }\end{array}$ & IARC \\
\hline $\mathbf{1}$ & carcinogenic \\
\hline 2A & probably carcinogenic \\
\hline 2B & possibly carcinogenic \\
\hline 3 & unclassifiable \\
\hline 4 & possibly not carcinogenic \\
\hline
\end{tabular}

\begin{tabular}{|c|c|}
\hline $\begin{array}{c}\text { evidence } \\
\text { level }\end{array}$ & SSK \\
\hline E3 & convincing evidence \\
\hline E2 & incomplete evidence \\
\hline E1 & $\begin{array}{c}\text { weak } \\
\text { evidence }\end{array}$ \\
\hline E0 & lack of evidence \\
\hline EN & evidence of lacking causality \\
\hline
\end{tabular}




\section{Perception}

Apart from cognitive restrictions the perception of given information is influenced also by several other aspects such as the presenter, the choice of information, its framing and wording.

The presenter plays an important role. The reason is that information is not just given in facts. Up to three quarter of information $(40 \%-75 \%)$ is transferred non-verbally by body language which is perceived and interpreted unknowingly. Since it is almost impossible to completely control voice, face, posture and movements, the own conviction cannot be hidden. Therefore, body language is unmasking. It may or may not be in agreement with the message. Therefore, to convince others needs to be convinced oneself. In addition, it should be acknowledged that patients may be in a stressful situation and need compassion rather than cool and unemotional listings of facts.

The choice of information is essential. Without being incorrect, for risk communication there are several parameters and endpoints on choice. As an example, the benefit of breast cancer chemoprevention could be quantified by the following parameters:

- Absolute risk reduction (ARR) in terms of reduced mortality from $6 \%$ to $3 \%$;

- Relative risk reduction (RRR) in terms of 50\% less mortality;

- Number of patients necessary to treat (NNT) to save one life, in this example 1 out of 33:

- Prolonged lifetime (PLT) which in this case is 4 months.

It is obvious that in breast cancer chemoprevention RRR is most impressive. However, in addition to selection of parameters there is also the question which health endpoint should be communicated [3].

Apart from chosen parameters the choice of the communicated health endpoints is also important. For example, at regular mammography screening the mortality from breast cancer is claimed to be reduced from 5 to 4 per 1000 women. However, it could be demonstrated that screening did not change women's overall mortality. This puzzling fact is explained by unintended side-effects causing one casualty per 1000 women such as due to triggered unnecessary therapy, carcinogenic X-ray exposure, medication and/or risks from unnecessary surgery. The reason is that up to a quarter $(15-25 \%)$ of detected tumours would not have caused any problems if they would have remained undetected and, hence untreated [3,11-13].

Consequently, in breast cancer screening the restriction to mortality fuels the controversy between advocates and opponents while other beneficial endpoints could help clarify the overall risk / benefit relationship such as by considering also improvements such as enabling more conservative therapy or maintaining life quality (see Table 4).

Framing information is important since perception of given information is influenced by the context in which it appears. The reason is that perception is relative. This is known from daily life. If someone wants to be perceived as attractive, it is a good strategy to be accompanied by a less attractive person. The same principle is valid also in risk communication by putting risks into a context. Talking about high-risk situations before informing about minor risks biases emotions such, that these risks are perceived less threatening. The context may also shift the emotional baseline towards concern or reassurance, respectively and, hence, influences risk perception.

Framing may also be realized by communicating either the good or bad side of a medal or both, such as giving success and/or failure rates, respectively. Gain and loss framing can considerably influence the acceptance of a message and shift patient's decision to one or another side. The reason is the imbalance of perception which means that negatives dominate over positives and potential losses over expected wins. Communicating a $90 \%$ healing rate can increase the acceptance while the same information given in terms of a $10 \%$ fatality rate can increase concern or refusal of an intervention - as widely seen in the debate about vaccination. For neutral information, risks as well as benefits should be reported.

Wording in terms of choice of words and their placement is important, in particular if wording is chosen that requires mental conversion.

Words may trigger memories, emotions, negative associations and even aversions. As an example, therapy using microwaves is more readily accepted than if it is said, it uses microwave radiation since the latter term is frequently associated with adverse X-rays or radioactivity and their associated radiation damages. For the same reason, initially the new imaging modality Nuclear Magnetic Resonance Tomography (NMRT) was renamed to Magnetic Resonance Imaging (MRI) to avoid associations with dangerous nuclear energy.

Negations should be used with care. They frequently require mental conversion and bias perception. The need for mental conversion is demonstrated by the following versions of the same message:

\section{1. "The intervention is not harmful." \\ 2. "The intervention is harmless."}

The first version is less convincing than the second one because it is biased by the negative perception of the word "not" as such and, in addition, it needs mental conversion of the term "not harmful" into the contrary, namely harmless. In contrast, the second version is straight forward and readily understood.

However, negations can be even trickier - as shown in the following versions of a message:

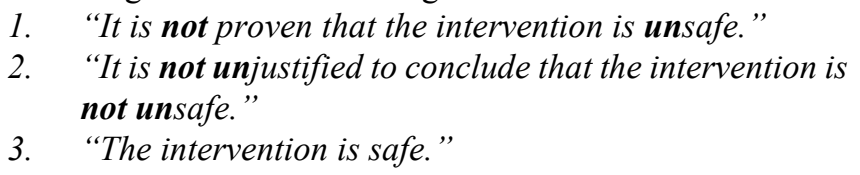

The first version includes two negations which impair 
understanding and due to perception imbalance leave a negative impression. The second version with double negations is even worse and a real challenge. It is very difficult to understand and frequently needs multiple reading to get the meaning (which is not possible in spoken conversation). The third version demonstrates the advantage of straight forward wording. It is easily and readily understood. As a consequence, while negations should be just avoided, double negations are an absolute no-go in any communication.

However, risk perception is not only characterized by the domination of negatives over positives but also by the timing of words. This means that the last part of a message dominates over the first one. Consequently, placement of words and sentences is important. This is demonstrated by the following two versions of a message:

1. "It is justified to conclude that risks are acceptable, but some uncertainty remains"

2. "Some uncertainty remains, but it is justified to conclude that risks are acceptable."

It can be readily seen that version two is more reassuring. In the first version the last part regarding uncertainty undermines the first part while in the second version the reassuring conclusion is dominating.

Comparisons are ambivalent tools. They can be valuable in risk communication if used properly. Of courses, to be understood and informative, also risks comparisons should be straight forward and avoid any need of mental conversion. However, the efficiency of comparisons is frequently over-estimated. Even more, inadequate comparisons in terms of comparing apples with oranges or mixing scales and dimensions may need mental conversion and even undermine understanding. Due to the subjective nature of risk perception comparisons are mostly not reassuring or improving risk acceptance.

However, if properly chosen, comparisons are useful in improving understanding the threat from an unknown risk factor and/or the relevance of a risk by illustrating orders of magnitudes or existing uncertainties. This is demonstrated by the following two versions of illustrating three orders of magnitudes:
1. The risk is 1000 fold lower which equals the difference between one cent and 10 dollar.

2. The risk is 1000 fold lower which equals the difference between a single drop and a pint of beer

The first comparison is problematic since it relies on the familiarity with money which may be justified or not, but needs mental conversion in terms of converting dollar into 100 cent and multiplying the result by 10 to get the 1000 fold. This is avoided in the second version which uses (usually) well-known quantities.

Comparing apples with oranges may even evolve negative emotions and aversions such as by comparing health risks with similar quantitative amount but quite different subjective risk perception such as by stating

the risks from magnetic fields from power lines are similar to coffee drinking or eating mixed pickles.

This comparison is frequently used, based on the fact that all risk factors have been classified by IARC into the same risk group, namely as possibly carcinogenic to humans, class 2B [6] but in the public risk from power lines are usually dramatically overestimated (at least in the planning and erection phase).

\section{Dos and Don'ts}

Today, physician's advice is no longer readily accepted but scrutinized by many patients. Hence, (also) physicians require sound and convincing arguing. It was already stated that risk communication to patients should be understandable, tailored, clear, concise, evidence-based, logic and targeted, having in mind talking to a virtual 14 year old child with limited literacy and numeracy and emotion-related impaired cognitive performance.

The overarching principle in risk communication is presenting a message in a straight forward way and avoiding any mental conversion. This objective is governing wording, quantification and illustration. A selection of dos and don'ts is presented in Table 2.

Table 2. Selected Dos and Don'ts in risk communication

\begin{tabular}{|c|c|c|}
\hline aspect & Don'ts & Dos \\
\hline quantification & Don't rely on verbs only. & Use verbs accompanied by numbers and plots. \\
\hline visualization & $\begin{array}{l}\text { Don't present complex diagrams e.g. with } \\
\text { suppressed zero, logarithmic scale. }\end{array}$ & $\begin{array}{l}\text { Use easy to understand first-glance } \\
\text { presentations, e.g. bar plots or pie charts. }\end{array}$ \\
\hline framing & Don't give one-sided information. & Provide risk and benefits. \\
\hline endpoints & Don't stick to mortality only. & $\begin{array}{l}\text { Choose comprehensive health-relevant } \\
\text { endpoints. }\end{array}$ \\
\hline risk characterization & $\begin{array}{l}\text { Don't use parameters which need mental } \\
\text { conversion. }\end{array}$ & $\begin{array}{l}\text { Select understandable parameters such as } \\
\text { absolute risk reduction. }\end{array}$ \\
\hline uncertainty & Don't ignore uncertainty. & Communicate uncertainty. \\
\hline comparisons & $\begin{array}{l}\text { Don't compare apples with oranges and } \\
\text { don't mix scales. }\end{array}$ & $\begin{array}{l}\text { Use comparable risk factors, the same scale and } \\
\text { same reference period. }\end{array}$ \\
\hline
\end{tabular}


Table 3. Inadequate and adequate examples of comparing risk of $2 \mathrm{mSv}$ accumulated dose o from breast cancer screening (10 mammograms in the age 50 to 68years)

\begin{tabular}{|c|}
\hline inadequate (risk) equivalents \\
\hline 75 min climbing \\
\hline $\begin{array}{c}200 \mathrm{~km} \text { biking } \\
\text { (better: Vienna-Budapest) }\end{array}$ \\
$\begin{array}{c}7,500 \mathrm{~km} \text { car driving } \\
\text { (better; Vienna-Peking) }\end{array}$ \\
$\begin{array}{c}18,000 \mathrm{~km} \text { air travel } \\
\text { (better: Anchorage-Kapstadt) }\end{array}$ \\
\hline smoking 75 cigarettes \\
\hline living 70 hours at age 60 \\
\hline working 1.5 years in a factory \\
\hline
\end{tabular}

\begin{tabular}{|c|}
\hline adequate (dose) equivalents \\
\hline 2-fold annual limit for general population \\
\hline annual environmental exposure \\
\hline 0,1 fold annual limit for workers \\
\hline 0.03 -fold annual limit of breast organ dose \\
\hline CT scan of the head \\
\hline 200 X-ray images of an extremity \\
\hline radiation dose from $1,000 \mathrm{~h}$ air travel \\
\hline
\end{tabular}

Using the example of breast cancer screening at women during age 50 to 69 good and bad examples of risk comparisons are given in Table 3 in terms of comparisons with factors of equivalent quantitative risk and with equivalent radiation doses, respectively. While the first may trigger emotions, need mental conversion and compares risks with quite different subjective perception, the second stays with the same physical quantity and is more readily understood. (The accumulated X-ray dose was estimated based on $4 \mathrm{X}$-rays images per investigation leading to a whole-body equivalent dose of about $0.2 \mathrm{mSv}$ per investigation which at biannual scanning during the age 50 69 years leads to a cumulated dose of $2 \mathrm{mSv}$ [12].)

\section{Examples of risk communication}

Risk communication is demonstrated at three different bodies dealing with breast cancer screening, namely the US National Cancer Institute (NCI), the Joint Committee of the Lower House of German Parliament (GBA) and the Swiss Medical Board (SMB) (Table 4). Due to space limitations the comparison is restricted to the given core messages only.

From the scientific point of view, breast cancer screening can save life but because of its side-effects also causes some deaths which, overall, leads to a balanced lethality. Therefore, full assessment would need including also other health-related endpoints and differentiation between various women's age groups. This situation complicates risk communication and explains different weighting and conclusions.

Communication of NCI [11] is characterized by a comprehensive view on risks and benefits and commenting on alternatives to $\mathrm{X}$-ray imaging. It aims at avoiding numerical information. Scientific terms are frequently replaced by general wording such as by using "breast cancer screening" instead of "mammography screening" or explaining the terms "false negative" and "false positive". However, there is still some inconclusiveness such as by staying with some special terms like "biopsy". Interestingly, NCI avoids a clear-cut conclusion but instead just recommends consulting a doctor and making an own decision.

In contrast, GBA [4] is more selective in comparing pros and cons. It favours the term "disadvantage" over the term "risk". There is no mention on alternatives. Unfortunately reader's cognitive capabilities are over-demanded by listing too many quantitative numerical details without any assistive illustrations (Table 4). However, it is noted that it aimed at staying with whole numbers such as by mentioning 1 induced death out of 200 screended women, however, at the expense that the basis for comparison (200 women instead of a whole decade) complicates mental conversion (of those who want it) into percentages. Overall, GBA recommends systematic mammography screening with biannual mammography in women ageing 50 - 69 years. To demonstrate the benefit of graphical assistance for improved understanding, Figure 6 is inserted in this paper to demonstrate how the pool of numbers given in GBA's "expectations" could have been visualized in a bar plot.

The SMB [13] starts with general Swiss figures on annual breast cancer incidence and mortality. However, they are not put into perspective by comparison with other health endpoints or with the overall number of inhabitants. The arguments pro and contra mammography screening are less detailed compared to NCI. Some selected benefits and disadvantages are highlighted, among them an economical cost/effect ratio which might not be extremely convincing to concerned women. There is no discussion on alternatives. However, SMB gives a clear-cut conclusion by not recommending systematic mammography screening and discouraging continuing related programs (Table 4). 
Table 4. Core messages regarding breast cancer (BC) screening from US National Cancer Institute (NCI 2014), and mammography screening (MS) from the Joint Committee of the Lower House of German Parliament (GBA 2010) and the Swiss Medical Board (SMB 2013)

\begin{tabular}{|c|c|c|}
\hline US National Cancer Institute & $\begin{array}{c}\text { Joint Committee of the Lower House of } \\
\text { German Parliament }\end{array}$ & Swiss Medical Board \\
\hline $\begin{array}{l}\text { Risks of BC screening: } \\
\text { - BC detection might not improve health or } \\
\text { prolong lifetime; } \\
\text { - False negatives: one out of five BC may be } \\
\text { missed; } \\
\text { - overdiagnosis: some detected and treated BC } \\
\text { may never have caused problems; } \\
\text { - False positives: risks due to subsequent } \\
\text { procedures; } \\
\text { - X-ray exposure is carcinogenic, younger at } \\
\text { higher risk, benefits outweigh risks beyond } 40 \\
\text { ages; } \\
\text { - Discomfort and pain during mammography. }\end{array}$ & $\begin{array}{l}\text { Disadvantages of MS screening: } \\
\text { - Suspicious findings may cause } \\
\text { unnecessary procedures (e.g. biopsy); } \\
\text { - In case of incurable malign BC } \\
\text { prolongation of suffer time rather than } \\
\text { life time; } \\
\text { - Treatment of BC which never would } \\
\text { have become a problem; }\end{array}$ & $\begin{array}{l}\text { Annually BC diagnosed in } 5,400^{1)} \text { Swiss } \\
\text { women, } 1,400 \text { related deaths } \\
\text { Disadvantages } \\
\text { - Overdiagnosis } \\
\text { - In } 100 \text { out of } 1000 \text { women false } \\
\text { positive outcome with related psychical } \\
\text { stress } \\
\text { - Unfavourable cost-effect ratio } \\
{ }^{1)} \text { In Switzerland there are } 4.1210^{6} \text { women }\end{array}$ \\
\hline $\begin{array}{l}\text { Benefits of BC screening vary among age groups: } \\
\text { - In older women with life expectancy }<5 \text { years } \\
\text { treating early BC reduces life quality without } \\
\text { increasing lifetime; } \\
\text { - In women }>65 \text { years BC detection causes more } \\
\text { diagnosis and anxiety } \\
\text { - Women with average BC risk don't benefit } \\
\text { from screening starting before age } 40 \text {. }\end{array}$ & $\begin{array}{l}\text { Benefits of mammography screening: } \\
\text { - Early BC detection allows more } \\
\text { conservative treatment (preserving } \\
\text { breasts, avoiding chemotherapy; } \\
\text { - Saving life in case of malign BC. }\end{array}$ & $\begin{array}{l}\text { Benefits of mammography screening: } \\
\text { - Contributes to early BC detection } \\
\text { - Improvs life quality } \\
\text { - Slight reduction in BC lethality: among } \\
1000 \text { women BC screening saves } 1-2 \\
\text { lives. }\end{array}$ \\
\hline $\begin{array}{l}\text { Alternatives to X-rays: } \\
\text { - MRI applies magnetic fields, but with high } \\
\text { false positive rate; } \\
\text { - Thermography with no exposure at all but } \\
\text { lacking clinical data on efficiency. }\end{array}$ & & \\
\hline $\begin{array}{l}\text { Conclusion: Consult doctor about individual } \mathrm{BC} \\
\text { risk and the need for } \mathrm{BC} \text { screening }\end{array}$ & $\begin{array}{l}\text { Expectations of MS over } 20 \text { years: } \\
\text { - Out of } 200 \text { women } 140 \text { no BC } \\
\text { identified; } \\
\text { - Out of remaining } 60 \text { women with } \\
\text { further investigation } 40 \quad \text { with } \\
\text { all-clearance; } \\
\text { - Out of remaining } 20 \text { women with } \\
\text { invasive diagnostics (e.g biopsy) in } 10 \\
\text { cases BC diagnosis; } \\
\text { - Out of } 190 \text { women } 3 \text { get BC anyway; } \\
\text { - Out of } 13 \text { women with BC } 3 \text { die, } 10 \\
\text { survive; } \\
\text { - Out of } 10 \text { survivors, } 8 \text { would have been } \\
\text { treated also without BC screening, } 1 \\
\text { would never had known about her BC; } \\
\text { - In one out of } 200 \text { women BC screening } \\
\text { was life-saving. } \\
\text { Conclusion: BC screening recommended }\end{array}$ & $\begin{array}{l}\text { Conclusion: Systematic BC screening is not } \\
\text { recommended; } \\
\text { Existing BC screening programs should be } \\
\text { terminated }\end{array}$ \\
\hline
\end{tabular}




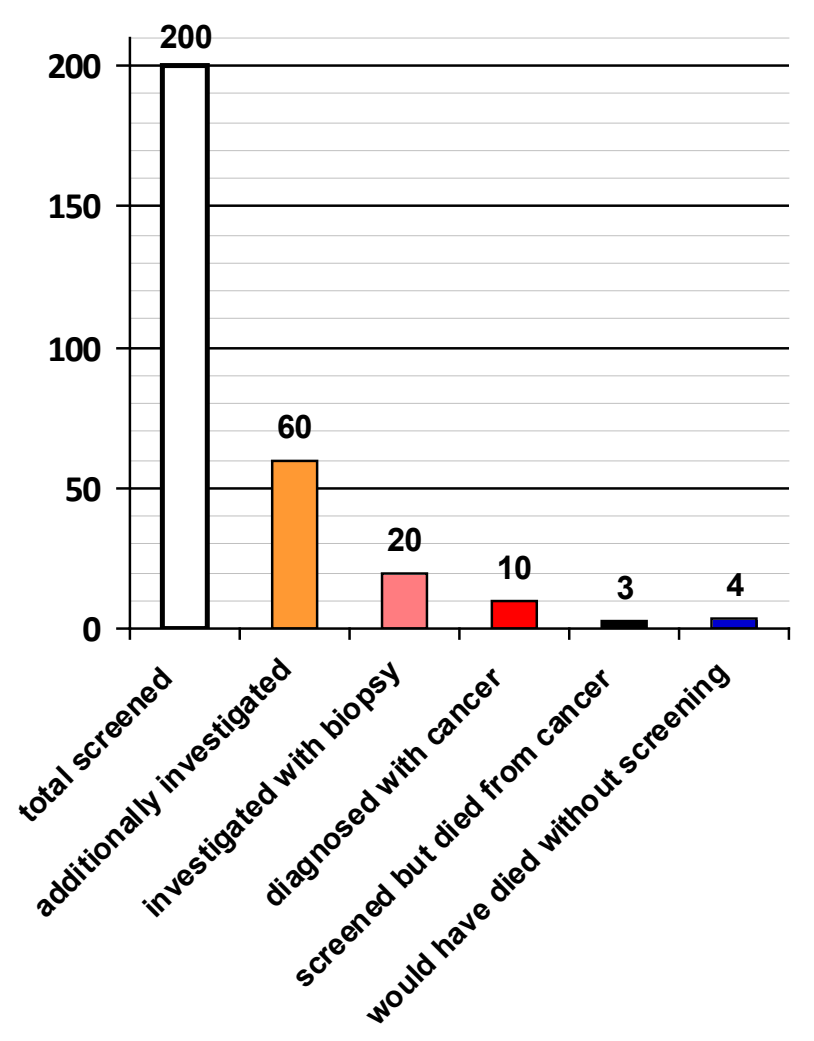

Figure 6. Visualization of data given in GBA report on the outcome of 20 years systematic mammography screening at women ageing 50-69, based on a cohort of 200 women, listed in "expectations" in Table 4 ,

\section{Conclusions}

Risk communication is more than just talking about an issue. It requires specific knowledge, tailoring and targeting information to the patient's needs and abilities, and observing communication rules. The most frequent mistake is underestimating the need for specific skills and ignoring the pitfalls and dos and don'ts of risk communication.

\section{Declaration of Conflict of Interest}

The author declares no conflict of interest.

\section{REFERENCES}

[1] EN 60601-1-11. Medical electrical equipment - Part 1-11General requirements for basic safety and essential performance- Collateral standard: Requirements for medical electrical equipment and medical electrical systems used in the home healthcare environment. CENELEC, Belgium, 2010
[2] FGSMB. Systematic mammography-screening. Swiss Medical Board, Switzerland, 2013, http://www.swissmedicalboard.ch

[3] B. Fischhoff, N.T. Brewer, J.S. Downs (editors). Communicating Risk and Benefits: An evidence-based user's guide. US Food and Drug Administration, 2011, http://www.fda.gov

[4] GBA (2010): Information on Mammography-Screening. Joint Committee of the Lower House of German Parliament. http://www.mammo-programm.de

[5] A. Grotlüschen, W. Riekmann (editors). Functional analphabetism in Germany. German Federation Anaphabetization and Basic Education, Vol. 10, Waxmann, Germany, 2012, http://www.blogs.epb.uni-hamburg.de

[6] IARC. Agents classified by the IARC monographs 1-100. International Agency for Research on Cancer, 2011, http://monographs.iarc.fr

[7] I.S. Kirsch, A. Jungeblut, L. Jenkins, A. Kolstad. Adult literacy in America. US Department of Education, USA, 2002

[8] M. Kutner, E. Greenberg, Y. Jin, C. Paulsen. The health literacy of America's adults. US Department of Education, USA, 2006

[9] N. Leitgeb. Improved approach of classifying evidence of health risks. Health Physics, Vol. 103 No.2, pp. 195-199, 2012

[10] S.O. Lilienfeld, K.C. Sauvigné, S.Y. Lynn, R.L. Cautin, R.D. Latzman, I..D. Waldman. Fifty psychological and psychiatric terms to avoid: A list of inaccurate, misleading, misused, ambiguous and logically confused words and phrases. Frontiers in Psychology, 2015, doi:10.3389/fpsyg.2015.01100

[11] NCI. Breast Cancer Screening. National Cancer Institute, USA, 2014,

http://www.cancer.gov/cancertopics/pdq/screening/ breast/Patient

[12] E.A. Nekolla, J. Griebel, G. Brix. Introduction of a mammography screening program in Germany. Consideration of benefits and risks. Radiologe Vol 45, pp. 245-254, 2005

[13] SMB. Systematic Mammography-Screening. Swiss Medical Board, Switzerland, 2013, http://www.swissmedicalboard.ch

[14] A. Tal, B. Wansink. Blinded with science. Trivial graphs and formulas increase persuasiveness and belief in product efficacy. Public understanding of science. 2014. pii:0963662514549688

[15] WHO. Radiation risk communication in pediatric imaging. WHO Workshop Report. Germany, 2012

[16] WHO. Establishing a dialogue on risks from electromagnetic fields. WHO, Switzerland, 2002

[17] M.V. Williams. Inadequate literacy as a barrier to asthma knowledge and self-care. Chest Vol. 114, No. 4, pp. 1008-1015, 1995 